\title{
Application of Fuzzy Expert Systems to Manage the Projects Time in Iranian Gas Refineries
}

\author{
Abbas Naderpour \\ Department of Civil Engineering \\ Islamic Azad University \\ Central Tehran Branch, Iran \\ Aba.Naderpour.eng@Iauctb.ac.ir
}

\author{
Javad Majrouhi Sardroud \\ Department of Civil Engineering \\ Islamic Azad University \\ Central Tehran Branch, Iran \\ J.Majrouhi.eng@Iauctb.ac.ir
}

\author{
Masood Mofid \\ Department of Civil Engineering \\ Sharif University of Technology \\ Tehran, Iran \\ Mofid@Sharif.edu
}

\begin{abstract}
The National Iranian Gas Company (NIGC) is one of the top ten gas companies in the gas industry in the Middle East and is comprised of 7 gas refineries. So this company needs to apply the most optimum time management methods to achieve its goals. Custom scheduling calculation of project planning uses the Critical Path Method (CPM) as a tool for Planning Projects activities. CPM is now widely used in planning and managing projects but in spite of its wide application, this method has a critical weak point of not taking into account the uncertainties in scheduling calculation. This article aims to present a precise method based on the application of Fuzzy Expert Systems in order to improve the Time Estimation Method in construction projects and in this regard, reviews the results of the implementation of this method in construction projects of Iranian Gas Refineries. The results show that the proposed method increases the accuracy of time estimation about 7 to 22 percent.
\end{abstract}

Keywords-Critical Path Method; Fuzzy Expert Systems; Uncertainty; Time Estimation Method

\section{INTRODUCTION}

Time management can be effective in a project when the project schedule is based on reasonable and comprehensive time estimation. In industries with complex processes such as gas refineries, considering limitations and risks involved in the project implementation and also many uncertainties that affect the project activities, the importance of the time management is great. As the ongoing projects are directly or indirectly linked with continuous production in gas refineries, operational condition and site classification based on the HSE risks, increases more uncertainties to the project schedule. Considering the very low reliability of planning with certainty and project control by this approach, using more secure methods for control and interaction with uncertainty is to be placed on the agenda. This article presents a method for implementing an extended method of CPM based on the application of fuzzy expert systems (FCPM) to manage schedule uncertainties in Iranian gas refinery projects. The concept of FCPM is explained by a real and applicable example and then, the proposed model and the method of its implementation in projects will be described.

\section{FUZZY CRITICAL PATH METHOD (FCPM)}

FCPM is an extension of Critical Path Method in terms of fuzzy approach. In this method, fuzzy function defines the time of project activities to manage their uncertainties. For understanding the main concepts of FCPM, consider the project network indicated in Figure 1. This project network is a part of a small one-story building construction planning that contained excavation, concreting and installing the building structures. The resistance system against the earthquake is A.D.A.S bracing. The description of all activities regarding the mentioned project is presented in Table I.

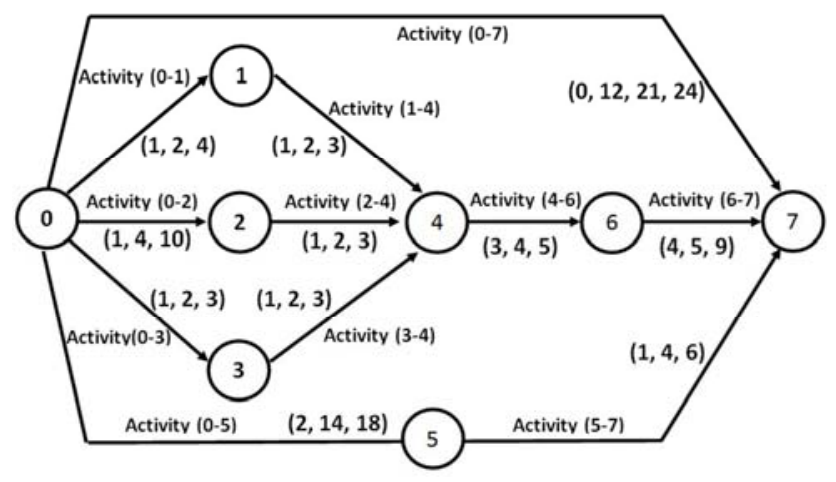

Fig. 1. CPM of small one-story building construction

As it could be seen from Table I, 10 out of whole 11 activity times have triangular fuzzy type format and only the remaining one (related to A.D.A.S braces) is in trapezoidal form. Equations (1) to (8) represent the stages of FCPM calculations of the project network. The calculations indicate that the project total time is the maximum of three fuzzy numbers (Eq.8). Consequently, in order to determine the project time, it is necessary to rank the fuzzy numbers and select the maximum.

$$
\operatorname{FES} 1=(0,0,0)+(1,2,4)=(1,2,4)
$$




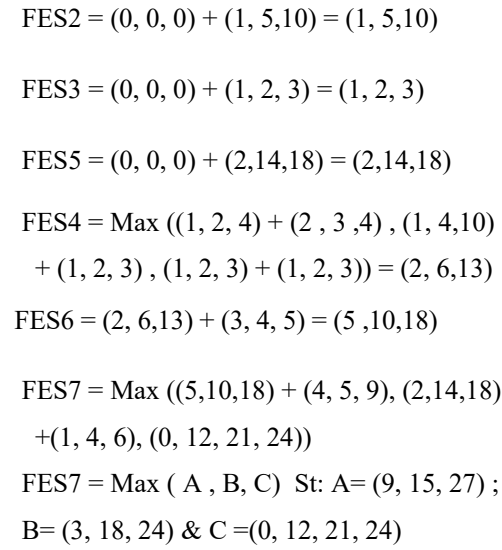

The calculations indicate that the project total time is the maximum of three fuzzy numbers (8). Consequently, in order to determine the project time, it is necessary to rank the fuzzy numbers and select the maximum. Since fuzzy numbers do not form a natural linear order (similar to real numbers) a key issue in applications of fuzzy set theory is how to compare fuzzy numbers. Various approaches have been developed for ranking fuzzy numbers up to now. Initially a method using the concept of maximizing set to order the fuzzy numbers was proposed in [1]. In [2] four indices which may be employed for the purpose of fuzzy ranking were introduced. In [3], an index for ordering (ranking) fuzzy numbers was proposed. In [4] a new method of fuzzy numbers ranking with integral value was described.

In [5], fuzzy sets were ranked based on the concept of existence of vibration frequencies. In [6] a new approach for ranking fuzzy numbers by distance method was proposed. In [7], ranking alternatives with fuzzy weights by maximizing and minimizing set was introduced. A new methods for ranked fuzzy sets was described in [8]. In [9], authors ranked fuzzy numbers with an area between centroid point and original point while in [10] authors used fuzzy distance measure for fuzzy numbers comparison in the same year. In [11], authors proposed another fuzzy ranking method based on distance method. In [12], authors ranked fuzzy numbers by sign distance. In [13], authors ranked fuzzy numbers by distance minimization. In [14], authors ranked trapezoidal fuzzy numbers with integral value. In [15], authors published the result of their research about fuzzy ranking. In [16], authors ranked fuzzy numbers with an area method using a radius of gyration in torsion stiffness. In [17], authors ranked trapezoidal fuzzy numbers based on mode, spread, and weight. In [18], authors improved the ranking method for fuzzy numbers based on centroid-index. In [19], authors proposed a new method based on angle measure and finally in [20] a new lexicographical approach for ranking fuzzy numbers was proposed.

For ranking the three fuzzy numbers of (8), five methods were considered. Table II shows the results of this ranking and Figure 2 compares the results in bar charts. Also, the project total time and critical path for each method are indicated in Table III
TABLE I. THE PROJECT INFORMATION OF ACTIVITIES

\begin{tabular}{|c|c|c|}
\hline Activity & Activity Description & Time (days) \\
\hline $0-1$ & Steel Bars Cutting & $(1,2,4)$ \\
\hline $0-2$ & Excavation & $(1,5,10)$ \\
\hline $0-3$ & Base Plate Making & $(1,2,3)$ \\
\hline $0-5$ & Making the Beams & $(2,14,18)$ \\
\hline $0-7$ & $\begin{array}{c}\text { Making \& Installation of } \\
\text { A.D.A.S braces }\end{array}$ & $(0,12,21,24)$ \\
\hline $5-7$ & Installing the Beams & $(1,4,6)$ \\
\hline $1-4$ & Making Reinforce Cage & $(1,2,3)$ \\
\hline $2-4$ & Foundation Forming & $(1,2,3)$ \\
\hline $3-4$ & Base Plate Installation & $(1,2,3)$ \\
\hline $4-6$ & Concreting & $(3,4,5)$ \\
\hline $6-7$ & $\begin{array}{c}\text { Columns Making and } \\
\text { Installation }\end{array}$ & $(4,5,9)$ \\
\hline
\end{tabular}

TABLE II. RESULTS OF FUZZY RANKING BY 5 METHODS

\begin{tabular}{|c|c|c|c|c|c|}
\hline \multirow{2}{*}{$\begin{array}{c}\text { Fuzzy Ranking } \\
\text { Method }\end{array}$} & \multicolumn{4}{|c|}{ Result of Ranking Method Calculation } \\
\cline { 2 - 6 } & A & B & C & \multicolumn{2}{|c|}{ Result } \\
\hline Choobineh \& Li & 17.5 & 18.33 & 15 & 18.33 & $\mathrm{C}<\mathrm{A}<\mathrm{B}$ \\
\hline Yager & 15.75 & 16.5 & 13.5 & 16.5 & $\mathrm{C}<\mathrm{A}<\mathrm{B}$ \\
\hline Cheng & 21.77 & 21.72 & 21.32 & 21.77 & $\mathrm{C}<\mathrm{B}<\mathrm{A}$ \\
\hline $\begin{array}{c}\text { Chen } \\
\text { \& Sanguansat }\end{array}$ & 17.1 & 18.75 & 15.6 & 18.75 & $\mathrm{C}<\mathrm{A}<\mathrm{B}$ \\
\hline $\begin{array}{c}\text { Abbasbandy } \\
\text { \& Hajjari }\end{array}$ & 15.75 & 15.73 & 14.25 & 15.75 & $\mathrm{C}<\mathrm{B}<\mathrm{A}$ \\
\hline
\end{tabular}

TABLE III. RESULTS OF PROJECT CRITICAL PATH

\begin{tabular}{|c|c|c|}
\hline Fuzzy Ranking Method & Project Critical Path & $\begin{array}{c}\text { project time } \\
\text { (days) }\end{array}$ \\
\hline Choobineh \& Li & $0-5-7$ & 18.33 \\
\hline Yager & $0-5-7$ & 16.5 \\
\hline Cheng & $0-2-4-6-7$ & 21.77 \\
\hline Chen \& Sanguansat & $0-5-7$ & 18.75 \\
\hline Abbasbandy \& Hajjari & $0-2-4-6-7$ & 15.75 \\
\hline
\end{tabular}

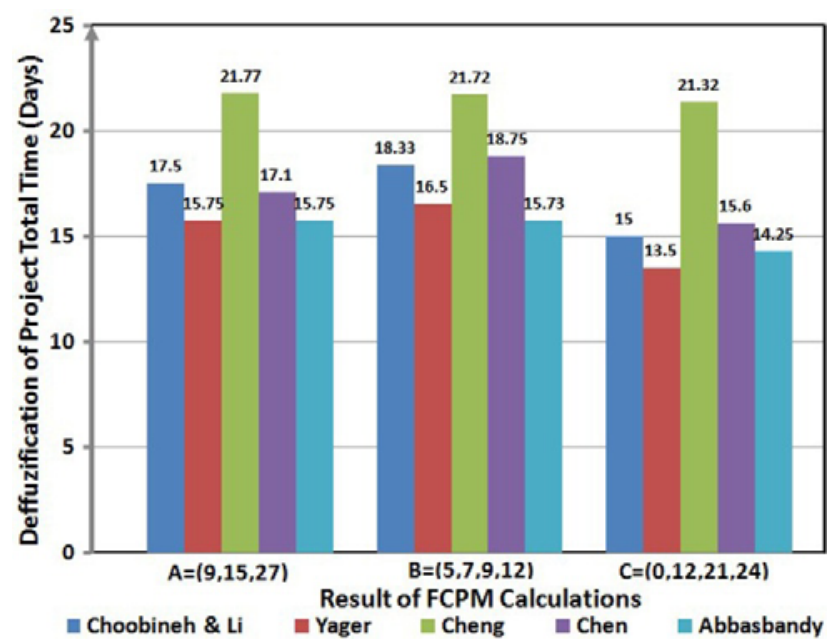

Fig. 2. Project time calculation by various fuzzy ranking methods

According to the results of FCPM calculations, selecting the fuzzy ranking method for project scheduling has a great influence on the determination of project total time and critical path. As a result, a suitable fuzzy ranking method, compatible 
to project nature should be considered by project management team.

\section{FUZZY TIME ESTIMATION}

Several methods have been proposed for finding the fuzzy time management. The main common topic in all of these methods is converting the classic time of project activities to fuzzy numbers for schedule calculation. For the reason that CPM calculation needs to compare the time of activities to determining critical path, ranking of fuzzy numbers is necessary. Consequently, fuzzy numbers ranking is the most important factor in these methods. In [21], authors introduced the preliminary concept of Fuzzy CPM. They presented the time of project activities by fuzzy set in the time space. Their method provides more direct processing verbally expressed opinions of experts. The significant problem not quite solved in their method was the question of deriving membership functions for activity duration times. In [22] algebraic operators were used to estimate the time of project activities and project critical path. In [23] a way to to compute total floats and find critical paths in a project network by the fuzzy approach was described. In [24], a methodology to calculate the fuzzy completion project time was presented and in [25] an extension of fuzzy schedule networks was proposed. New methods were recently introduced in [26]. They proposed a method for ranking fuzzy numbers without the need for any assumptions and used both positive and negative values to define ordering which is applied to CPM.

In [27], authors presented an approach to the critical concept in a network with fuzzy activity times. In [28], a taxonomy of fuzzy graphs that treated fuzziness in vertex existence, edge connectivity and edge weight was presented. In [29], a new approach to implementing a fuzzy CPM for activity networks based on statistical confidence interval estimates and a ranking method for level fuzzy numbers was introduced. In [30], authors presented an algorithm to perform fuzzy critical path analysis for project network problem. In [31], authors presented another method to calculate fuzzy critical paths and critical activities and activity delays and in [32] authors extended some results for interval numbers to the fuzzy case for determining the possibility distributions to describe latest starting time of activities. In [33], authors proposed an approach based on the extension principle and linear programming (LP) formulation to critical path analysis in networks with fuzzy activity durations. In [34], authors introduced the problems of determining possible values of earliest and latest starting times of an activity in networks with minimal time lags and imprecise durations that are represented by means of the interval of fuzzy numbers. In [35], authors proposed a new approach based on fuzzy critical path calculation. They used fuzzy arithmetic and the fuzzy ranking method to determine the fuzzy critical path of the project network without converting the fuzzy activity times to classical numbers and compared their method with other methods. In [36], authors proposed a new method of fuzzy critical path analysis based on the centroid of centroids of fuzzy numbers and in [37] authors proposed new algorithms identify the critical path in a fuzzy environment of project network.

\section{PROPOSED FUZZY BASE METHOD}

The uncertainties that must be managed in each project are categorized into two main groups; the First group includes probable uncertainties which are managed by risk management and the second group covers non-probable uncertainties that are related to project nature and its complexity. Many industries, such as gas refineries manage probable uncertainties in their projects by risk management but in the field of non-probable uncertainties, actions are very scarce. This article considers the managing of non-probable uncertainties in gas refineries projects. The diagram of proposed model is shown in Figure 3.

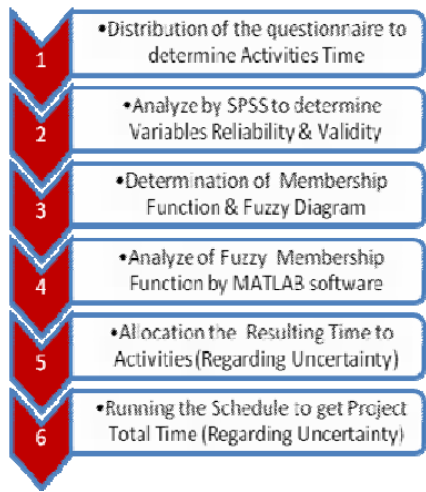

Fig. 3. Diagram of the proposed model

For implementing the models, at first, two professional questionnaires were distributed between a professional team which was selected by the staff of 70 contractors, consultant and employer companies. The first questionnaire was designed to identify effective factors such as site organization, weather, labor skills and quality of equipment on doing project activities. Then obtained Linguistic variables were translated into mathematical measures. For instance, the questionnaire was designed for excavation activity is presented in Table IV.

TABLE IV. QUESTIONNAIRE OF EXCAVATION ACTIVITY

\begin{tabular}{|c|c|c|c|c|}
\hline \multicolumn{5}{|c|}{$\begin{array}{l}\text { Please determine the effect of each factor in the time of excavation } \\
\text { Activity. }\end{array}$} \\
\hline \multicolumn{5}{|c|}{ 1- Excavation Equipment (Hand Tools, loader, Backhoe, Excavator, Dozer) } \\
\hline Very Poor $\square$ & Poor $\square$ & Medium $\square$ & High $\square$ & Very High $\square$ \\
\hline \multicolumn{5}{|c|}{ 2- Climatic Condition (Very Warm, Warm, Moderate, Cold, Very Cold) } \\
\hline Very Poor $\square$ & Poor $\square$ & Medium $\square$ & High $\square$ & Very High $\square$ \\
\hline \multicolumn{5}{|c|}{ 3- HSE Criteria (Classification of site in Operational Zones) } \\
\hline Very Poor $\square$ & Poor $\square$ & Medium $\square$ & High $\square$ & Very High $\square$ \\
\hline \multicolumn{5}{|c|}{ 4- Classification of Rock (Earthy, Soft, Moderate, Hard, Very Hard) } \\
\hline Very Poor $\square$ & Poor $\square$ & Medium $\square$ & High $\square$ & Very High $\square$ \\
\hline \multicolumn{5}{|c|}{ 5- The level of underground water in Meter $(>15,10-15,5-10,1-5,<1)$} \\
\hline Very Poor $\square$ & Poor $\square$ & Medium $\square$ & High $\square$ & Very High $\square$ \\
\hline \multicolumn{5}{|c|}{ 6- Depot Distance in Meter $(>10000,1000-10000,500-1000,100-500,<100)$} \\
\hline Very Poor $\square$ & Poor $\square$ & Medium $\square$ & High $\square$ & Very High $\square$ \\
\hline \multicolumn{5}{|c|}{ 7- Depth of Excavation in Meter $(>15,10-15,5-10,1-5,<1)$} \\
\hline Very Poor $\square$ & Poor $\square$ & Medium $\square$ & High $\square$ & Very High $\square$ \\
\hline \multicolumn{5}{|c|}{ 8- years of driver Experience of $(>20,15-20,10-15,5-10,<5)$} \\
\hline Very Poor $\square$ & Poor $\square$ & Medium $\square$ & High $\square$ & Very High $\square$ \\
\hline
\end{tabular}


As it can be seen in Table IV, the value of the Linguistic variables is classified into 5 types (Figure 4). As it could be seen in Table IV, a large number of factors are considered to estimate the time of excavation activity. To examine the reliability of the questionnaire, data analysis was done by SPSS. The results of this analysis are shown in Table V. According to SPPS analysis, the Cronbach's alpha (Reliability Index) was 0.387 , while it should be greater than 0.7 . The results show that factors $2,3,5,6$ and 8 do not have an effective influence on the timing of excavation activity. So these factors were eliminated and the calculations were repeated. In the new analysis, the index rose up to 0.888 which is desirable. So the main factors of excavation activity are Excavation Equipment, Classification of Rock and Depth of Excavation. In the next step, the second questionnaire which relates to estimating activity durations was distributed among team members. After summing up the results of the first and second questionnaires, obtained results were examined by a team of experts (composed of 8 expert project managers) to determine its content validity. Then, according to satisfactory results, the structural validity of survey questionnaires was evaluated by Factor Analysis method. According to the KMO index, the acceptable construct validity of research was approved. The analysis results are summarized in Table VI. Also, the results of the total variance of analysis explained that these three factors are not reducible to the number of agent-less (Table VII).

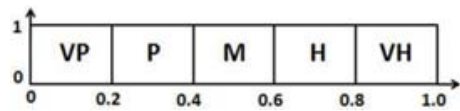

Fig. 4. The value of the linguistic variables classification

TABLE V. RESULTS OF RELIABILITY INDEX CALCULATED BY SPSS

\begin{tabular}{|c|c|c|c|c|}
\hline & $\begin{array}{c}\text { Scale Mean if } \\
\text { Item Deleted }\end{array}$ & $\begin{array}{c}\text { Scale Variance } \\
\text { if Item Deleted }\end{array}$ & $\begin{array}{c}\text { Total } \\
\text { Correlation }\end{array}$ & $\begin{array}{c}\text { Cronbach's } \\
\text { Alpha if Item } \\
\text { Deleted }\end{array}$ \\
\hline S01 & 12.11 & 5.951 & 0.443 & 0.290 \\
\hline S02 & 13.75 & 8.639 & 0.136 & 0.449 \\
\hline S03 & 13.75 & 9.231 & 0.110 & 0.505 \\
\hline S04 & 11.86 & 5.460 & 0.621 & 0.190 \\
\hline S05 & 13.25 & 8.120 & 0.000 & 0.526 \\
\hline S06 & 13.68 & 8.300 & 0.109 & 0.457 \\
\hline S07 & 12.75 & 6.861 & 0.368 & 0.153 \\
\hline S08 & 13.61 & 7.803 & 0.276 & 0.404 \\
\hline
\end{tabular}

TABLE VI. THE RESULTS OF KMO TEST

\begin{tabular}{|c|c|c|}
\hline Kaiser-Meyer-Olkin Measure of Sampling Adequacy & 0.692 \\
\hline \multirow{3}{*}{ Bartlett's Test of Sphericity } & Approx. Chi-Square & 13.522 \\
\cline { 2 - 3 } & $\mathrm{df}$ & 3 \\
\cline { 2 - 3 } & Sig. & 0.003 \\
\hline
\end{tabular}

TABLE VII. THE RESULTS OF TOTAL VARIANCE

\begin{tabular}{|c|c|c|c|}
\hline \multirow{2}{*}{ Component } & \multicolumn{3}{|c|}{ Total Variance Explained } \\
\cline { 2 - 4 } & Total & \% of Variance & Cumulative \% \\
\hline 1 & 1.823 & 46 & 46 \\
\hline 2 & 1.076 & 28 & 74 \\
\hline 3 & 1.041 & 26 & 100 \\
\hline
\end{tabular}

According to the results obtained from computing of the Pearson Correlation coefficient, the correlation between these factors is also desirable. Table VIII indicates related results.

TABLE VIII. THE RESULTS OF CORRELATION INDEX

\begin{tabular}{|c|c|c|c|c|}
\hline \multicolumn{2}{|c|}{ Correlation Results } & S01 & S04 & S07 \\
\hline \multirow{3}{*}{ S01 } & Pearson Correlation & 1 & 0.910 & 0.576 \\
\cline { 2 - 5 } & Sig. (2-tailed) & & 0.000 & 0.001 \\
\cline { 2 - 5 } & $\mathrm{N}$ & 28 & 28 & 28 \\
\hline \multirow{3}{*}{ S04 } & Pearson Correlation & 0.910 & 1 & 0.511 \\
\cline { 2 - 5 } & Sig. (2-tailed) & 0.000 & & 0.005 \\
\cline { 2 - 5 } & N & 28 & 28 & 28 \\
\hline \multirow{3}{*}{ S05 } & Pearson Correlation & 0.576 & 0.511 & 1 \\
\cline { 2 - 5 } & Sig. (2-tailed) & 0.001 & 0.005 & \\
\cline { 2 - 5 } & N & 28 & 28 & 28 \\
\hline
\end{tabular}

In later stages of the proposed model, membership functions of these factors were drawn according to the second questionnaire. The second questionnaire is about estimating the time of each activity based on the experience of the professional team. In this research, Fuzzy diagrams were of triangular and trapezoidal types. In the present example, Figures 5 to 7 indicate the Fuzzy membership functions of excavation activity factors. These diagrams are considered as the input of analysis.

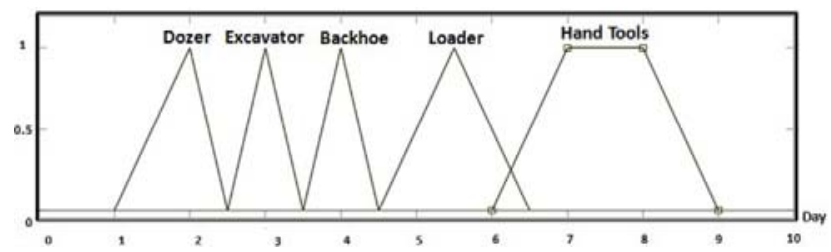

Fig. 5. Fuzzy membership of excavation equipment factor

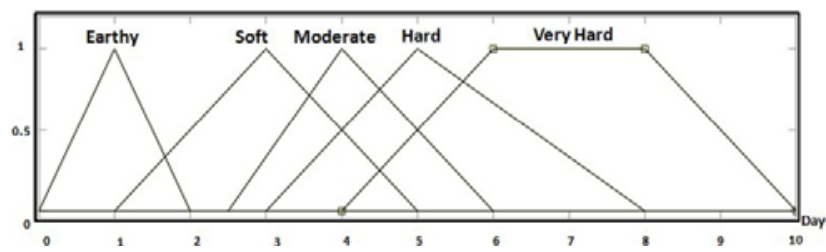

Fig. 6. Fuzzy membership of classification of rock factor

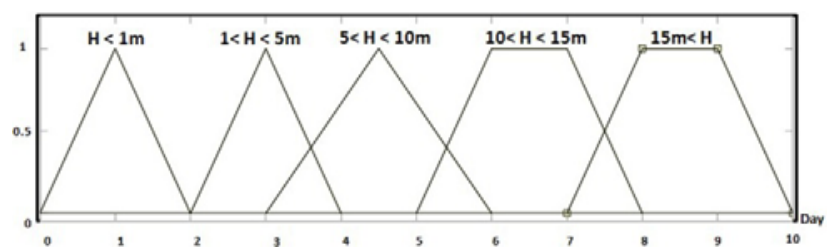

Fig. 7. Fuzzy membership of excavation depth factor

Then the results of the previous step as input were analyzed in Fuzzy Toolbox of MATLAB. This toolbox follows a Rule Base System. Analysis of model is presented in Figure 8. As it 
can be seen in Figure 8, inputs are processed by a smart and rule base system.

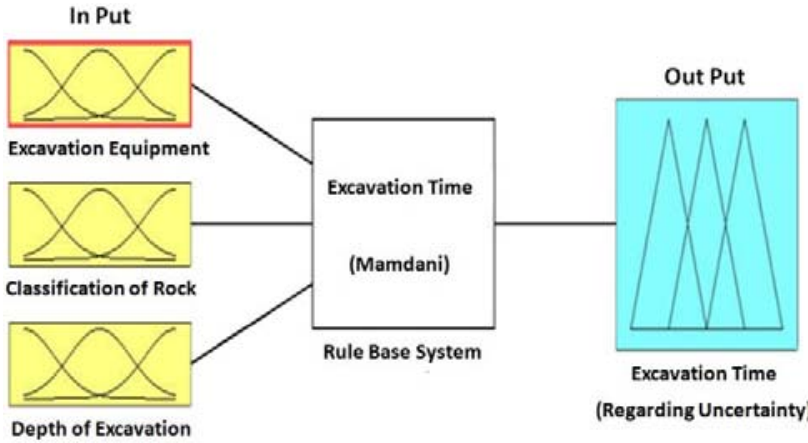

Fig. 8. A pictorial view of analysis model in MATLAB

"IF ...Then ..." rules were set by the expert team in Rule Base system. For example, for these three factors, about 125 operating modes may occur. Three states of these rules are observed in Table IX and Software environment can be seen in Figure 9.

TABLE IX.

AN EXAMPLE OF ANALYSIS RULES

\begin{tabular}{|c|l|}
\hline Rule No & \multicolumn{1}{c|}{ The Rule } \\
\hline Rule 1 & $\begin{array}{l}\text { If Excavation Equipment is a Dozer and Classification of } \\
\text { Rock is Very Hard and Depth of Excavation is more than 15 } \\
\text { meter ThenThe Time of Excavation is Very Long. }\end{array}$ \\
\hline Rule 2 & $\begin{array}{l}\text { If Excavation Equipment is a Backhoe and Classification of } \\
\text { Rock is Soft and Depth of Excavation is Less than 1 meter } \\
\text { ThenThe Time of Excavation is Very Short. }\end{array}$ \\
\hline Rule 3 & $\begin{array}{l}\text { If Excavation Equipment is a Dozer and Classification of } \\
\text { Rock is Hard Or Depth of Excavation is between 1 to 5 meter } \\
\text { ThenThe Time of Excavation is Moderate. }\end{array}$ \\
\hline
\end{tabular}

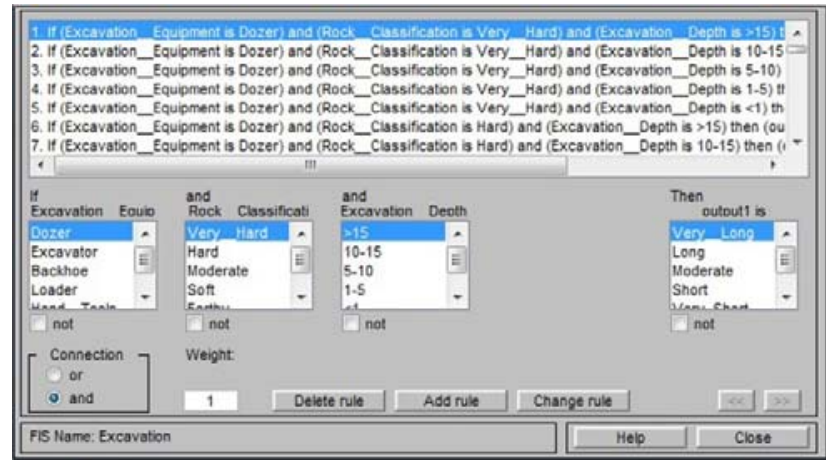

Fig. 9. A pictorial view of setting the rules in the software

After analysis, the duration of activities under uncertainty and fuzzy approach can be achieved. For example, this time for an above-mentioned activity (Excavation) will be 4.5 days for each 200 cubic meters of concrete. (Figures 10-11). Finally, after calculating the time of all activities by this method, project schedule was run and the total time of project was calculated.

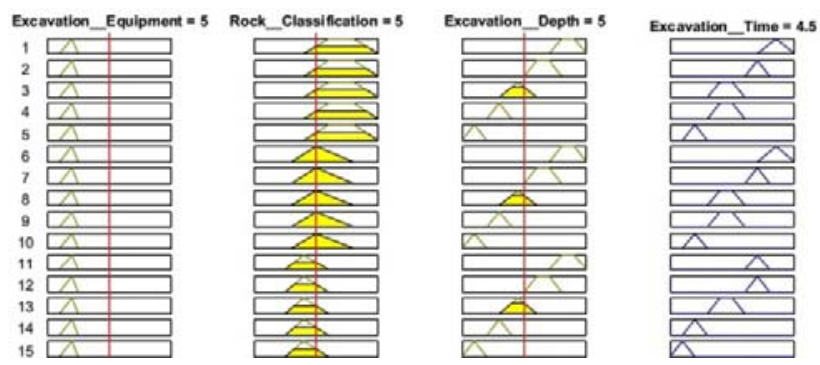

Fig. 10. A pictorial view of analysis output

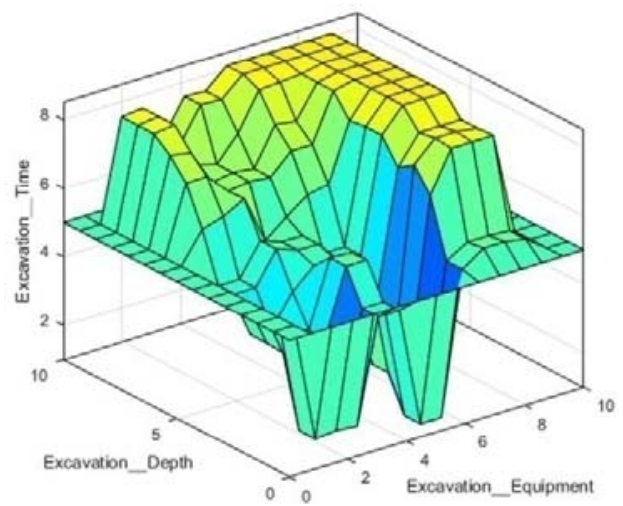

Fig. 11. A pictorial view of MATLAB output diagram

\section{RESULTS}

The proposed model of the research has been implemented in one gas refinery in the North East of Iran. The study period was between 2014 and 2016 and the population of this study was composed of 30 projects by Cochran formula. The result of the research shows the estimated project duration is about 7 to 22 percent closer to actual time. Figure 12 indicates the percent of improvement in project time estimation.

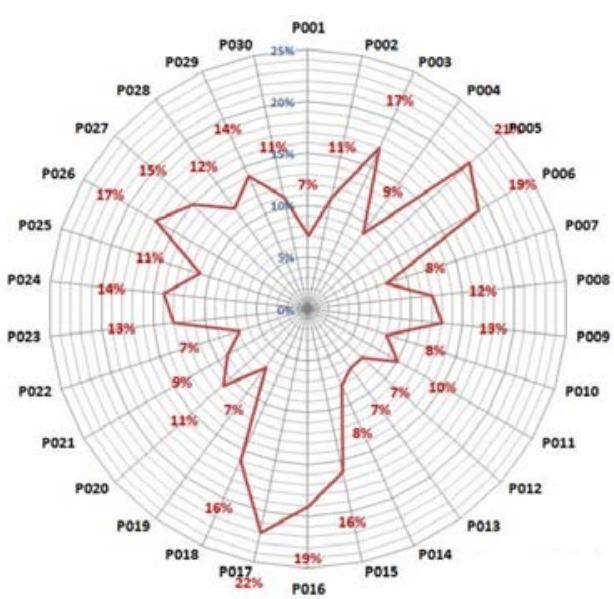

Fig. 12. Diagram of improvement in project time estimation new method

\section{CONCLUSION}

This study investigated a new method for precise time estimation in construction projects of the Iranian Gas Refineries. A gas refinery has a complicated process and 
ongoing projects are directly or indirectly linked with continuous production in this industry. Consequently managing the project time is a critical issue and considering the very low reliability of the project planning with certainty, using more secure models for control and interact with uncertainty is a necessity. It is obvious that successful project time management should be based on comprehensive time estimation. Therefore, considering the uncertainty in the estimation of project time is the main object. From the above discussion, the following conclusions were derived:

1. Many industries, such as gas refineries manage probable uncertainties in their projects by risk management but in the field of non-probable uncertainties, actions are very scarce.

2. This research considered the managing of non-probable uncertainties in gas refineries projects by a proposed method based on Fuzzy Critical Path Method.

3. The result of the implementation of proposed method shows that the accuracy of project time estimation increases about 7 to 22 percent. Finally, due to successful results of this research, it has been suggested that the proposed method could be generalized to other industries projects.

\section{REFERENCES}

[1] R. Jain, "Decision-Making in the presence of fuzzy variables", IEEE Transactions on Systems Man and Cybernetics, Vol. 6, pp. 698-703, 1976

[2] R. Yager, "A procedure for ordering fuzzy subsets of the unit interval", Information Science, Vol. 24, pp. 143-161, 1981

[3] F. Choobineh, H. Li, "An index for ordering fuzzy numbers", Fuzzy Sets and Systems, Vol. 5, pp.1-19, 1985

[4] S. L. Liou, M. J. Wang, "Ranking fuzzy numbers with integral value", Fuzzy Sets, and Systems, Vol. 50, pp 247-255, 1992

[5] P. T. Chang, E. S. Lee, "Ranking of Fuzzy Sets Based on the Concept of Existence", Computers and Mathematics with Applications, Vol. 27, No 9, pp.1-21, 1994

[6] C. H. Cheng, "A new approach for ranking fuzzy numbers by distance method", Fuzzy Sets and Systems, Vol. 95, pp. 307-317, 1998

[7] P. A. Raj, A. Kumar, "Ranking alternatives with fuzzy weights using maximizing set and minimizing set", Fuzzy Sets and Systems, Vol. 105 , pp. $365-375,1999$

[8] J. S. Yao, F. T. Lin, "Fuzzy critical path method based on signed distance ranking of fuzzy numbers", IEEE Transactions on Systems, Man, and Cybernetics-Part A: Systems and Humans, Vol. 30, No 1, pp.76-82, 2000

[9] T. C. Chu, C. T. Tsao, "Ranking fuzzy numbers with an area between the centroid point and the original point", Computers and Mathematics with Applications, Vol. 43, pp.111-117, 2002.

[10] L. Tran, L. Duckstein, "Comparison of fuzzy numbers using a fuzzy distance measure", Fuzzy Sets and Systems, Vol. 130, pp. 331-341, 2002

[11] C. Lucas, B. Asady, "A new method for ranking of fuzzy numbers through using distance method", Journal of Teacher Training University, Vol. 3, pp. 83-88, 2003

[12] S. Abbasbandy, B. Asady "Ranking of fuzzy numbers by sign distance", Information Sciences, Vol. 176, pp. 2405-2416, 2006

[13] B. Asady, A. Zendehnam, "Ranking fuzzy numbers by distance minimization", Applied Mathematical Modelling, Vol. 31, pp. 25892598, 2007

[14] C. Chen, H. Tang, "Ranking Non-Normal P-Norm Trapezoidal fuzzy numbers with integral value", Computers and Mathematics with Applications, Vol. 56, pp. 2340-2346, 2008

[15] S. Abbasbandy, T. Hajjari, "A new approach for ranking of trapezoidal fuzzy numbers", Computers and Mathematics with Applications, Vol. 57, pp. 413-419, 2009
[16] S. Chen, K. Sanguat, "Analyzing fuzzy risk analysis based on a new fuzzy ranking method between generalized fuzzy numbers", Expert Systems with Applications, Vol. 38, pp. 2163-2171, 2011

[17] P. Rao, N. Ravi Shankar, "Fuzzy critical path analysis based on centroid of centroids of fuzzy numbers and new subtraction method", International Journal of Mathematics in Operational Research, Vol. 5, No. 2, pp. 205-224, 2013

[18] L. Q. Dat, S. Y Chou, "An Improved Ranking Method for Fuzzy Numbers Based on the Centroid-Index", International Journal of Fuzzy Systems, Vol. 14, pp. 413-419, 2012

[19] M. Barkhordary Ahmadi, "Ranking of fuzzy numbers based on angle measure", International Journal of Information, Security and System Management, Vol. 3, No 1, pp. 259-265, 2014

[20] U. A. Sharma, "New lexicographical approach for ranking fuzzy numbers", Mathematical Theory and Modeling, Vol. 5, No 2, pp. $143-153,2015$

[21] S. Chanas, J. Kamburowski, "The use of fuzzy variables in PERT", Fuzzy Sets and Systems, Vol. 5, No 1, pp. 11-19, 1981

[22] I, Gazdik, "Fuzzy network planning-FNET", IEEE Transactions on Reliability, Vol. 32, No 3, pp. 304-313, 1981

[23] S. H. Nasution, "Fuzzy critical path method", IEEE Transactions on Systems, Man and Cybernetics, Vol. 24, pp. 48-57, 1994

[24] S. Chang, Y. Tsujimura, T. Tazawa, "An efficient approach for large scale project planning based on fuzzy Delphi Method", Fuzzy Sets and Systems, Vol. 76, pp. 277-288, 1995

[25] P. Lorterapong, O. Moselhi, "Project-network analysis using fuzzy sets theory", Journal of Construction Engineering and Management, Vol. 122, pp. 308-318, 1996

[26] J. S. Yao, F. T. Lin, "Fuzzy Critical path Method Based on SignedDistance Ranking and Statistical Confidence-Interval Estimates", IEEE Transactions on Systems, Vol. 30, No. 1, pp. 76-82, 2000

[27] S. Chanas, P. Zielinski, "Critical path analysis in the network with fuzzy activity times", Fuzzy Sets and Systems, Vol. 122, pp. 195204, 2001

[28] M. Blue, B. Bush, J. Puckett, "Unified approach to fuzzy graph problems", Fuzzy Sets and Systems, Vol. 125, pp. 355-368, 2002

[29] J. S. Yao, F. T. Lin, "Fuzzy critical path method based on signed distance ranking of fuzzy numbers", The Journal of supercomputing, Vol. 24, pp. 305-325, 2003

[30] G. S. Liang, T. C. Han, "Fuzzy critical path for project network", Information and Management Sciences, Vol. 15, No 4, pp. 29-41, 2004

[31] A. Oliveros, A. Robinson, "Fuzzy Logic Approach for Activity Delay Analysis and Schedule Updating", Journal of Construction and Management, Vol. 131, No. 1, pp. 42-51, 2005

[32] S. Chanas, P. Zielinski, "Critical path analysis in the network with fuzzy activity times", Fuzzy Sets and Systems, Vol. 122, pp. 195204, 2006

[33] S. P. Chen, Y. J. Hsueh, "A simple approach to fuzzy critical path analysis in project networks, Applied Mathematical Modelling", Vol. 32, No. 7, pp. 1289-1297, 2008

[34] S. H. Yakhchali, S. H. Ghodsy Pour, "On latest starting times of activities in networks with imprecise durations and generalized precedence relations", Applied Mathematical Modelling, Vol. 34, No. 8, pp. 2044-2058, 2010

[35] S. Sathish, K.Ganessan, "A simple approach to fuzzy critical path analysis in project networks", Journal of Scientific \& Engineering Research, Vol. 2, No. 12,pp. 1-6, 2011

[36] P. Rao, N. Ravi Shankar, "Fuzzy critical path analysis based on centroid of centroids of fuzzy numbers and new subtraction method", International Journal of Mathematics in operational research, Vol. 5, No. 2, pp. 205-244, 2013

[37] S. Elizabet, L. Sujatha, "Project Scheduling Method using Triangular fuzzy numbers and triangular fuzzy numbers", Applied Mathematical Science, Vol. 9, No. 4, pp. 185-198, 2015 